\title{
Direct Synthesis of Mesoporous Sulfated Silica-Zirconia Catalysts with High Catalytic Activity for Biodiesel via Esterification
}

\author{
Xiao-Rong Chen, ${ }^{\dagger, \star}$ Yi-Hsu Ju, ${ }^{\S}$ and Chung-Yuan Mou ${ }^{* \dagger \dagger}$ \\ Department of Chemistry, National Taiwan University, Taipei 106, Taiwan, College of Chemistry and Chemical \\ Engineering, Nanjing University of Technology, Nanjing 210009, China, and Department of Chemical \\ Engineering, National Taiwan University of Science and Technology, Taipei 106, Taiwan
}

Received: June 24, 2007; In Final Form: October 3, 2007

\begin{abstract}
A solid acid material of high loading of sulfated zirconia on mesoporous silica SBA-15 has been successfully synthesized by a direct-synthesis under strong acidic condition. The materials were characterized by powder $\mathrm{X}$-ray diffraction, $\mathrm{N}_{2}$ adsorption-desorption, $\mathrm{UV}$-visible diffuse reflectance spectroscopy, transmission electron microscopy (TEM), ICP-mass, and $\mathrm{NH}_{3}$ temperature-programmed-desorption (TPD). The zirconia content and well-ordered mesostructure of $\mathrm{SiO}_{2}-\mathrm{SZ}$ are controllable by tuning the molar ratios of sulfate to zirconia and silica to zirconia. UV-visible spectra and TEM observations confirm the incorporation of zirconium (IV) onto the mesoporoes framework. Acidity is enhanced in comparison with unsupported sulfated zirconia. Much improved catalytic performance under mild temperature condition in the esterification of lauric acid and palmitic acid with the direct-synthesis $\mathrm{SiO}_{2}-\mathrm{SZ}$ catalyst was observed as compared to un-supported $\mathrm{SZ}$. The good catalytic performance of the sulfated silica-zirconia materials is attributed to a higher dispersion of zirconia to give higher acid site density and also to better tolerance of water. The solid acid catalytic materials have many advantages over liquid acids in its environmentally friendliness and easy separation.
\end{abstract}

\section{Introduction}

Biodiesel is an environmentally friendly fuel as it is made from renewable resources and $\mathrm{CO}_{2}$ neutral. It is usually derived from the esterification of free fatty acids or the transesterification of triglycerides with methanol or ethanol. In the industrial transesterification process, homogeneous base catalysts, such as sodium and potassium hydroxide, are often used. The basecatalyzed process suffers from some limitations of feedstock. The contents of free fatty acid in the feedstock need to be lower than $0.5 \mathrm{wt} \%$, otherwise soap formation seriously hinders the production of biodiesel. ${ }^{1,2}$ Esterification is thus needed for converting long-chain fatty acids into esters. ${ }^{3,4}$ Esterifications are conventionally catalyzed homogeneously using concentrated sulfuric acid, which is however corrosive and poor for waste discharge..$^{5}$ Solid acid catalysts are preferable, eliminating corrosion problems and offering easy separation of catalysts from the products by filtration. ${ }^{6}$ Recently, there have developed various solid acids for the esterification of long chain fatty acids; these include sulfonated carbonized sugar, ${ }^{7}$ sulfated zirconia, ${ }^{8}$ and organosulfonic acid mesoporous silica. ${ }^{9}$ However, the activities of most of these heterogeneous catalysts are still low in comparison with sulfuric acid. It is desirable to further develop good solid acid catalyst with high catalytic activity and stability for the esterification of fatty acid.

There are several considerations in the development of a strong solid acid for the purpose. First, the catalyst needs to be highly dispersed in order to bring out a large number of active acid sites. Second, mesoporosity in the catalyst would be able to accommodate the relatively larger molecules of fatty acid.

\footnotetext{
* Corresponding author. E-mail: cymou@ntu.edu.tw.

National Taiwan University.

$\doteqdot$ Nanjing University of Technology.

$\S$ National Taiwan University of Science and Technology.
}

Finally, the catalyst needs to be water-tolerant since water is a byproduct of the esterification process.

Previously, Rothenberg and co-workers have screened various solid acids (zeolites, ion-exchange resins, and mixed oxides) for the esterification of fatty acid with methanol at 130-180 ${ }^{\circ} \mathrm{C} .{ }^{8,10}$ Under reactive distillation conditions of esterification, there are many advantages in heterogeneous catalysts. ${ }^{10}$ They found sulfated zirconia to be the most promising candidate in terms of activity and stability. As a solid acid catalyst, sulfated zirconia offers a number of advantages such as strong acidity and stability which has been extensively exploited in gas-phase catalysis. In our previous works on alkane isomerization, it is known that the catalytic performance can be greatly enhanced by dispersing sulfated zirconia onto mesoporous silica MCM41. ${ }^{11}$ This is because the high surface area of the mesoporous silica provides better dispersion of the solid acid sulfated zirconia and thus provided more acid sites. ${ }^{11}$ Mesorosity is especially important in liquid-state catalysis for easy transport of the bulky molecules, such as long chain fatty acids. Mbaraka et al. found that the activity of mesoporous materials functionalized with acidic groups was greatly dependent on the pore dimensions for the esterification of free fatty acids. ${ }^{12}$ Liu et al. reported decreasing activity and reusability of catalyst for increasing chain length of carboxylic acid. ${ }^{13}$ For the liquid-phase heterogeneous catalytic reaction, the small pore size and poor hydrothermal stabilities of MCM-41 limit its application in esterification of long-chain free fatty acids. It is desirable to have larger pore-size materials as the supports. Mesoporous SBA-15 materials are good candidates as supports for the dispersion of sulfated zirconia because of the properties of their large pore sizes and hydrothermal stabilities. ${ }^{14}$

Postsynthesis is a method usually used for the incorporation of zirconia onto mesoporous silica. ${ }^{15-17}$ However, postsynthesis grafting is more cumbersome and may destroy the uniform 
mesostructure and block the channels. A direct synthesis would be relatively simple and give uniform mesostructure. ${ }^{18,19}$ However, it is difficult to introduce zirconia into mesoporous SBA-15 with high yield because SBA-15 materials are usually synthesized under strong acidic condition.

In this paper, we report a direct-synthesis method for the incorporation of zirconia onto mesoporous SBA-15 under strong acidic condition giving high zirconia content. In the synthesis process, both the zirconia and sulfate source were added to the initial synthesis gel mixture of SBA-15. Because of the introduction of sulfate, a small amount of sulfur exists in the final products (named as $\mathrm{SiO}_{2}-\mathrm{SZ}$ ). It was found the amount of $\mathrm{SO}_{4}{ }^{2-}$ plays an important role in stabilizing the mesostructure of SBA-15 and tuning the yield of tetragonal zirconia. The catalytic performances of $\mathrm{SiO}_{2}-\mathrm{SZ}$ samples are investigated for the esterification of long-chain free fatty acids. Unsupported sulfated zirconia (SZ) is also synthesized to compare its catalytic activity with $\mathrm{SiO}_{2}-\mathrm{SZ}$ catalysts to show a higher conversion of free fatty acids for the later.

\section{Experimental Section}

2.1. Synthesis. A series of mesoporous $\mathrm{SiO}_{2}-\mathrm{SZ}$ materials were synthesized using $\mathrm{EO}_{20} \mathrm{PO}_{70} \mathrm{EO}_{20}$ (Pluronic P123, Aldrich) as a template. In a typical synthesis, $1.0 \mathrm{~g}$ of P123 was dissolved in $30 \mathrm{~mL}$ of $\mathrm{H}_{2} \mathrm{O}$ to obtain a clear solution, and $5 \mathrm{~mL}$ of $37 \mathrm{wt}$ $\% \mathrm{HCl}$ (Acros) was added. Then $2.3 \mathrm{~mL}$ of tetraethyl orthosilcate (TEOS, Acros) and the required amount of zirconium propoxide (Aldrich, 70\%) and ammonium sulfate (Acros) were added. The mixture was stirred for $20 \mathrm{~h}$ at $40{ }^{\circ} \mathrm{C}$ and further aged at $100{ }^{\circ} \mathrm{C}$ for $24 \mathrm{~h}$. The product was collected by filtration, dried, and calcined at $650{ }^{\circ} \mathrm{C}$ for $5 \mathrm{~h}$. Samples with different $\mathrm{SO}_{4}{ }^{2-} / \mathrm{Zr}$ molar ratio are prepared at a fixed $\mathrm{Si} / \mathrm{Zr}$ molar ratio of 2, and samples are denoted as $\mathrm{SiO}_{2}-\mathrm{SZ}(2, x \mathrm{~S})$, where $x$ means the value of the $\mathrm{SO}_{4}{ }^{2-} / \mathrm{Zr}$ molar ratio. At a fixed molar ratio $\mathrm{SO}_{4}{ }^{2-} / \mathrm{Zr}$ of 1 , samples prepared at different $\mathrm{Si} / \mathrm{Zr}$ molar ratios are denoted as $\mathrm{SiO}_{2}-\mathrm{SZ}(y, 1 \mathrm{~S})$, where $y$ means the value of the $\mathrm{Si} / \mathrm{Zr}$ molar ratio.

For comparison, a SBA-15 sample was prepared the same way as $\mathrm{SiO}_{2}-\mathrm{SZ}$ except that $\mathrm{Zr}(\mathrm{OPr})_{4}$ and $\left(\mathrm{NH}_{4}\right)_{2} \mathrm{SO}_{4}$ were not added. Unsupported sulfated zirconia (SZ) was also prepared by the impregnation method. A total of $5 \mathrm{~g}$ of $\mathrm{Zr}\left(\mathrm{NO}_{3}\right)_{4} \cdot 8 \mathrm{H}_{2} \mathrm{O}$ (Acros) was dissolved in $50 \mathrm{~mL}$ water, followed by precipitation of zirconium hydroxide at $\mathrm{pH} 10$ using a $5 \mathrm{M} \mathrm{NH}_{3}$ solution. The resulting $\mathrm{Zr}(\mathrm{OH})_{4}$ was washed with water, impregnated with $1.2 \mathrm{M} \mathrm{H}_{2} \mathrm{SO}_{4}$, then dried for $10 \mathrm{~h}$ at $100{ }^{\circ} \mathrm{C}$, and calcined in air at $650{ }^{\circ} \mathrm{C}$ for $5 \mathrm{~h}$.

2.2. Characterization. The powder X-ray diffraction patterns of $\mathrm{SiO}_{2}-\mathrm{SZ}$ materials were collected on a Scintag X1 diffractometer using $\mathrm{Cu} \mathrm{KR}(k, 0.1541 \mathrm{~nm})$ radiation. Nitrogen adsorption and desorption isotherms were measured at $-196{ }^{\circ} \mathrm{C}$ with a Mircomeritics ASAP 2010 instrument. The samples were outgassed for $6 \mathrm{~h}$ at $150{ }^{\circ} \mathrm{C}$ under vacuum in the degas port of the adsorption analyzer. The specific surface area was calculated with the use of the Brunauer-Emmett-Teller (BET) method. The pore size distributions were obtained by the BarrettJoyner-Halenda $(\mathrm{BJH})$ method. The total pore volume was calculated at $P / P_{0}=0.91$. Transmission electron microscopy (TEM) micrographs were taken with a Hitachi H-7100 instrument operating at $75 \sim 100 \mathrm{kV}$ or a Philips CM200 at $200 \mathrm{kV}$. UV-vis diffuse reflectance spectra were measured with a Perkin-Elmer Lambda 18 spectrometer equipped with a PrayingMantis diffuse reflectance attachment. $\mathrm{BaSO}_{4}$ was used as the reference. Elemental analysis was determined by ICP-mass technique using a Perkin-Elmer Elan-6000 instrument. Sulfur
TABLE 1: Synthesis Conditions and Texture Properties of $\mathrm{SiO}_{2}-\mathrm{SZ}$ Calcined at $650{ }^{\circ} \mathrm{C}$

\begin{tabular}{|c|c|c|c|c|c|c|c|c|c|}
\hline \multicolumn{2}{|c|}{$\mathrm{SO}_{4}{ }^{2-} / \mathrm{Zr}^{a}$} & \multicolumn{2}{|c|}{$\mathrm{Si} / \mathrm{Zr}^{a}$} & \multirow[b]{2}{*}{$\begin{array}{l}\mathrm{SA}_{\mathrm{BET}} \\
\left(\mathrm{m}^{2} / \mathrm{g}\right)\end{array}$} & \multirow[b]{2}{*}{$\begin{array}{l}d_{100}{ }^{2} \\
(\mathrm{~nm})\end{array}$} & \multirow[b]{2}{*}{$\begin{array}{c}a_{0}^{c} \\
(\mathrm{~nm})\end{array}$} & \multirow[b]{2}{*}{$\begin{array}{c}D_{\mathrm{p}} \\
(\mathrm{nm})\end{array}$} & \multirow[b]{2}{*}{$\begin{array}{c}T_{\mathrm{w}}{ }^{d} \\
(\mathrm{~nm})\end{array}$} & \multirow[b]{2}{*}{$\begin{array}{c}V_{\mathrm{p}}{ }^{e} \\
\left(\mathrm{~cm}^{3} / \mathrm{g}\right)\end{array}$} \\
\hline gel & product & gel & product & & & & & & \\
\hline 1 & 0.044 & 2 & 3.01 & 556 & 10.01 & 11.56 & 8.8 & 2.76 & 0.85 \\
\hline 0.5 & 0.043 & 2 & 3.60 & 490 & 10.61 & 12.25 & 10.0 & 2.25 & 0.98 \\
\hline 0.25 & 0.058 & 2 & 6.56 & 575 & 10.61 & 12.25 & 10.7 & 1.55 & 1.25 \\
\hline 0 & 0 & 2 & 15.2 & 628 & & & 5.0 & & 0.78 \\
\hline 1 & 0.078 & 3 & 5.85 & 667 & 9.73 & 11.24 & 8.4 & 2.84 & 0.94 \\
\hline 1 & 0.063 & 4 & 6.74 & 672 & 9.91 & 11.45 & 8.9 & 2.55 & 1.03 \\
\hline
\end{tabular}

${ }^{a}$ Molar ratio. ${ }^{b} d_{100}$ calculated from Bragg equation: $2 d \sin \theta=n \lambda$ $(\lambda=0.1541 \mathrm{~nm}) .{ }^{c} a_{0}=2 d_{100} /\left[\right.$ graphic1]. ${ }^{d} T_{\mathrm{w}}=a_{0}-D_{\mathrm{p}} \cdot{ }^{e} \mathrm{~N}_{2}$ adsorption volume at $P / P_{0}=0.91$.

analysis was done with a Heraeus VarioEL-III instrument. Temperature-programmed desorption was carried out on a Mircomeritics ASAP 2910 instrument to study acidity of catalysts. In a typical experiment, before $\mathrm{NH}_{3}$ adsorption, $0.1 \mathrm{~g}$ of calcined $\mathrm{SiO}_{2}-\mathrm{SZ}(2,1 \mathrm{~S})$ sample was pretreated at $400{ }^{\circ} \mathrm{C}$ in flowing $\mathrm{He}$ for $1 \mathrm{~h}$. The $\mathrm{NH}_{3}$ adsorption was carried out at $120{ }^{\circ} \mathrm{C}$, and the desorption of $\mathrm{NH}_{3}$ was started at $120{ }^{\circ} \mathrm{C}$ and continued until $600{ }^{\circ} \mathrm{C}$ at $10{ }^{\circ} \mathrm{C} / \mathrm{min}$.

2.3. Catalytic Studies. Reactions were performed in a stirred batch reactor with samples withdrawn periodically for analysis using an Agilent 6890 gas chromatograph fitted with a $30 \mathrm{~m}$ HP-5ms capillary column. Two kinds of fatty acids were used: lauric acid (Acros, 99.5\%) and palmitic acid (Sigma, 95\%). Anhydrous methyl alcohol (MeOH; Mallickrodr, 99.9\%) was used without further purification. The reaction mixtures used in the study had a catalyst/fatty acid/MeOH weight ratio of 2:10: 100. Esterification reactions were performed at $\sim 68{ }^{\circ} \mathrm{C}$, which is the boiling temperature of the reaction mixtures.

\section{Results}

3.1. Structure and Composition. First, we present the composition and textural properties of the catalyst materials. We will first investigate the effect of varying sulfate loading. Then will fix the sulfate content and study the effect of varying zirconia loading.

Effect of Varying Sulfate Loading. As the initial $\mathrm{Si} / \mathrm{Zr}$ molar ratio was fixed at 2 in the synthesis process, the influence of sulfate content on the textural properties of sulfated silicazirconia is shown in Table 1. When no sulfate groups are presented in the synthesis gel, a mixture of $\mathrm{SiO}_{2}-\mathrm{ZrO}_{2}$ is obtained. Zirconia content in the final product is much lower, and the $\mathrm{Si} / \mathrm{Zr}$ molar ratio is only 15.20 . The $\mathrm{Si} / \mathrm{Zr}$ molar ratio in the products decreases from 6.6 to 3.0 as the $\mathrm{SO}_{4}{ }^{2-} / \mathrm{Zr}$ ratio in the gel is increased from 0.25 to1.0. At first, this seems to be counterintuitive. Zirconium exists as complex ploy-oxo ions in aqueous solution. ${ }^{20}$ However, under strong acidic condition, zirconium exists mostly in the cationic form rather than the corresponding polyoxo species. Sulfate groups show a high complexing ability and behave like network formers, bridging different chains together. ${ }^{21}$ So zirconium can combine with ammonium sulfate to form the polyoxo ions as $\left[\mathrm{Zr}(\mathrm{OH})_{2}\left(\mathrm{SO}_{4}{ }^{2-}\right)_{x}\right.$ $\left.\left(\mathrm{H}_{2} \mathrm{O}\right)_{y}\right]_{n}{ }^{n(2-2 x)}$. These polyoxo ions can interact strongly with the solution silicate species which are negatively charged under the synthetic condition. The decrease of sulfates in the synthetic gel results in a reduction of zirconium sulfated species formed and thus lowered the zirconia loading in the final product.

Table 1 also lists the $\mathrm{SO}_{4}{ }^{2-} / \mathrm{Zr}$ molar ratio in the calcined product. All samples were calcined at the temperature of $650{ }^{\circ} \mathrm{C}$. Although the $\mathrm{SO}_{4}{ }^{2-} / \mathrm{Zr}$ molar ratio was high in the gel, only a small amount of sulfur exists in the $\mathrm{SiO}_{2}-\mathrm{SZ}$ samples. 


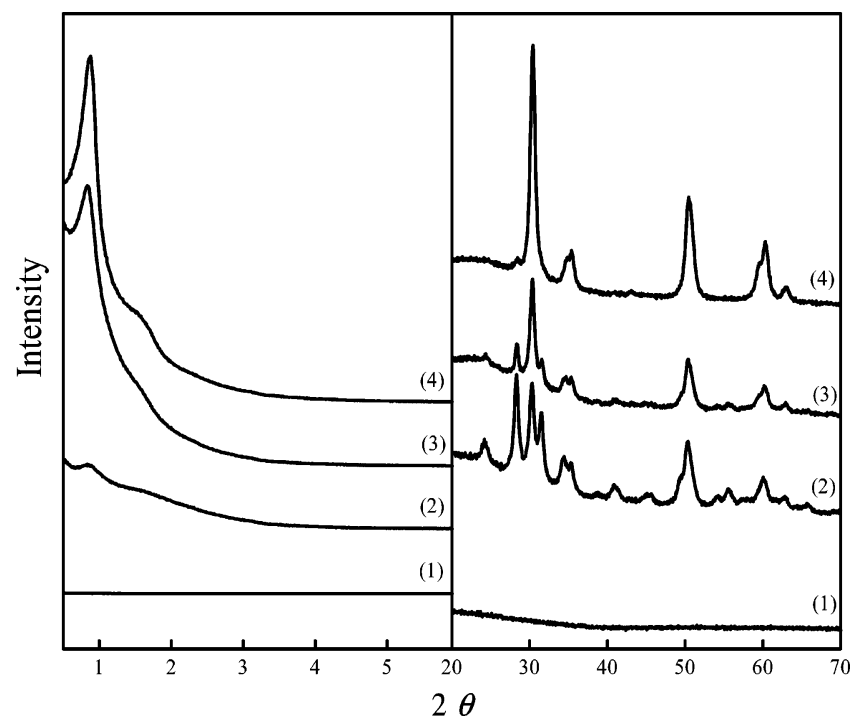

Figure 1. $\mathrm{XRD}$ patterns of $\mathrm{SiO}_{2}-\mathrm{SZ}(2, x \mathrm{~S})$ at $x=\mathrm{SO}_{4}{ }^{2-} / \mathrm{Zr}$ molar ratios of (1) 0 , (2) 0.25 , (3) 0.5 , and (4) 1 . (a) The small angle and (b) the high angle.

The influence of sulfate content on the structural quality of the $\mathrm{SiO}_{2}-\mathrm{SZ}$ can be observed by looking at the (100) reflection in the small angle XRD patterns. From Figure 1a, the XRD patterns of $\mathrm{SiO}_{2}-\mathrm{SZ}(2, x \mathrm{~S})$ shows that the reduction of gel sulfate content results in a decrease of the intensity of the (100) reflection which means the hexagonal mesostructures are less ordered. At $\mathrm{SO}_{4}{ }^{2-} / \mathrm{Zr}=0$, no (100) reflection peak is observed in $\mathrm{SiO}_{2}-\mathrm{ZrO}_{2}$. It indicates the hexagonal mesostructure is not formed at all. Figure $1 \mathrm{~b}$ also shows the high angle XRD patterns of $\mathrm{SiO}_{2}-\mathrm{SZ}(2, x \mathrm{~S})$ samples. For $\mathrm{SiO}_{2}-\mathrm{SZ}(2,1 \mathrm{~S})$, zirconia mainly shows the tetragonal phase, indicated by the main peak at $2 \theta$ $=30.2^{\circ}$. Two small peaks of monoclinic zirconia $\left(2 \theta=28.5^{\circ}\right.$, $31.5^{\circ}$ ) appeared in $\mathrm{SiO}_{2}-\mathrm{SZ}(2,0.5 \mathrm{~S})$. As the ratio of $\mathrm{SO}_{4}{ }^{2-} / \mathrm{Zr}$ decreased to 0.25 , the intensity of monoclinic zirconia greatly increased suggesting more tetragonal zirconia transformation to monoclinic zirconia. As the ratio of $\mathrm{SO}_{4}{ }^{2-} / \mathrm{Zr}$ further decreases to zero, no crystal phases of zirconia are observed. The XRD patterns of $\mathrm{SiO}_{2}-\mathrm{ZrO}_{2}(2,0 \mathrm{~S})$ at high angle shown in Figure 1b suggest the sulfate groups favor the formation of well-ordered hexagonal mesostructures and stabilize the tetragonal zirconia.

The $\mathrm{N}_{2}$ adsorption-desorption isotherms of calcined $\mathrm{SiO}_{2}-$ $\mathrm{SZ}(2, x \mathrm{~S})$ catalysts $\left(\right.$ at $650^{\circ} \mathrm{C}$ ) are shown in Figure 2. At higher gel sulfate content of $\mathrm{SO}_{4}{ }^{2-} / \mathrm{Zr}=1$ and 0.5 , the isotherms exhibit a typical pattern IV according to IUPAC classification and H1-type hysteresis loops. The sharp steps of capillary condensation of $\mathrm{N}_{2}$ are observed at the relative pressure $\left(p / p_{0}\right)$ of $0.6 \sim 0.8$ in the isotherms of $\mathrm{SiO}_{2}-\mathrm{SZ}(2,1 \mathrm{~S})$ and $\mathrm{SiO}_{2}-\mathrm{SZ}$ (2, 0.5S). For $\mathrm{SiO}_{2}-\mathrm{SZ}(2,0.25 \mathrm{~S})$ and $\mathrm{SiO}_{2}-\mathrm{ZrO}_{2}(2,0 \mathrm{~S})$, the $\mathrm{H} 1$-type hysteresis loop becomes more narrow. It is interpreted that the shortened mesopore channels and broadened pore size distributions are presented in the samples of $\mathrm{SiO}_{2}-\mathrm{SZ}(2,0.25 \mathrm{~S})$ and $\mathrm{SiO}_{2}-\mathrm{ZrO}_{2}(2,0 \mathrm{~S})$.

In addition to the nanoparticle form of tetragonal zirconia, some $\mathrm{Zr}$ may be incorporated in the framework of silica. UVvisible diffuse reflectance spectroscopy has been successfully used to determine the dispersion of $\mathrm{Zr}(\mathrm{IV})$ in the mesoporous silica matrix. It was reported that zirconium-containing mesoporous silica exhibits an absorption peak at $205 \sim 215 \mathrm{~nm} .^{22} \mathrm{In}$ $\mathrm{Zr}-\mathrm{MCM} 48$, there is an absorption at $207 \mathrm{~nm} .^{23}$ In both works, the absorption peak near $210 \mathrm{~nm}$ is attributed to the ligand-tometal charge transfer (LMCT) from an $\mathrm{O}^{2-}$ to an isolated $\mathrm{Zr}^{4+}$

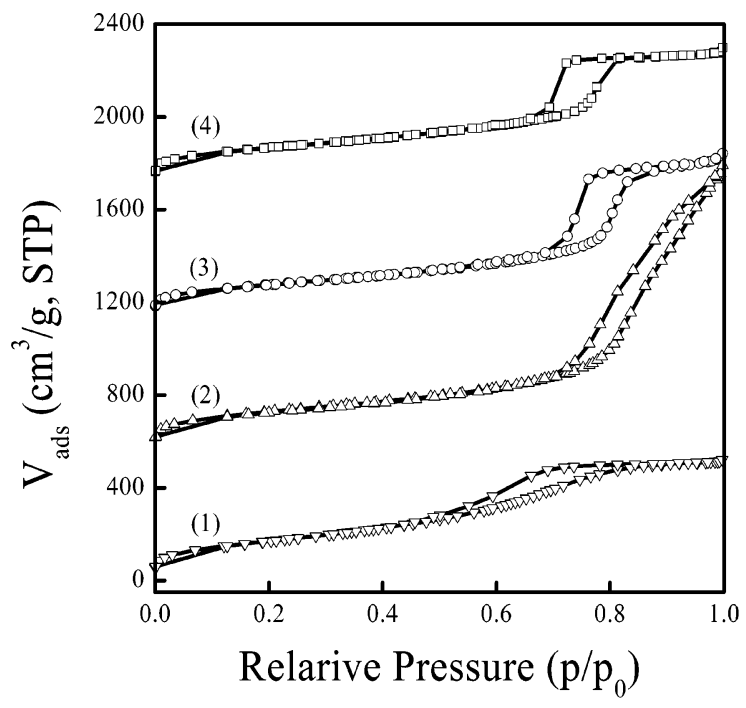

Figure 2. Nitrogen adsorption isomerms of $\mathrm{SiO}_{2}-\mathrm{SZ}(2, x \mathrm{~S})$ at $x=$ $\mathrm{SO}_{4}^{2-} / \mathrm{Zr}$ molar ratios of (1) 0 , (2) 0.25 , (3) 0.5 , and (4) 1.

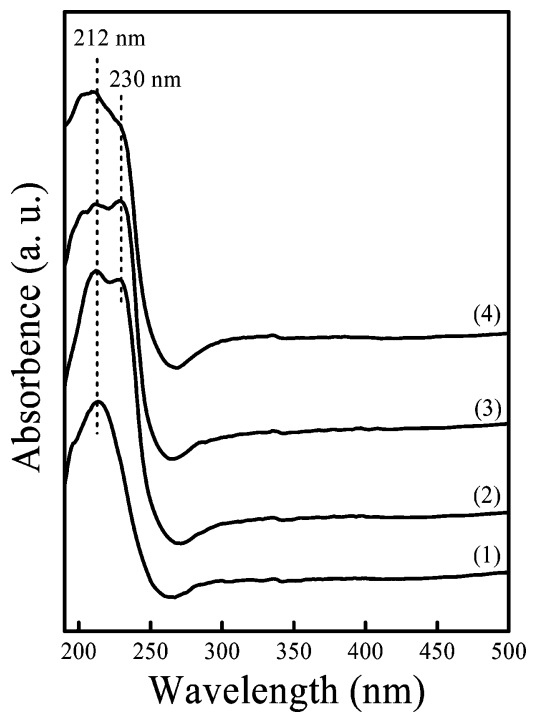

Figure 3. $\mathrm{UV}-$ vis DR spectra of $\mathrm{SiO}_{2}-\mathrm{SZ}(2, x \mathrm{~S})$ at $x=\mathrm{SO}_{4}{ }^{2-} / \mathrm{Zr}$ molar ratios of (1) 0 , (2) 0.25 , (3) 0.5 , and (4) 1 .

ion in a tetrahedral configuration. $\mathrm{ZrO}_{2}$ gives an absorption peak at $230 \mathrm{~nm}$, which is assigned to $\mathrm{Zr}-\mathrm{O}-\mathrm{Zr}$ linkage. Figure 3 shows UV-vis spectra of sulfated zirconia-silica samples with various $\mathrm{SO}_{4}{ }^{2-} / \mathrm{Zr}$ molar ratio. $\mathrm{SiO}_{2}-\mathrm{ZrO}_{2}$ without sulfate groups shows only a band at $212 \mathrm{~nm}$, inferring that no crystalline $\mathrm{ZrO}_{2}$ are detected in the mixture oxides of $\mathrm{SiO}_{2}-\mathrm{ZrO}_{2}$ and isolated $\mathrm{Zr}(\mathrm{IV})$ species are incorporated into the mesoporous silica wall. This result is well in accordance with the high angle XRD pattern for $\mathrm{SiO}_{2}-\mathrm{ZrO}_{2}(2,0 \mathrm{~S})$ where no zirconia phase is detected. With the sulfate added to the synthesis gels, $\mathrm{SiO}_{2}-$ $\mathrm{SZ}(2, x \mathrm{~S})$ samples exhibit two bands at 212 and $230 \mathrm{~nm}$, respectively. These results suggest that some $\mathrm{Zr}(\mathrm{IV})$ species are incorporated into the walls of the mesostructured silica in $\mathrm{SiO}_{2}-$ $\mathrm{SZ}(2, x \mathrm{~S})$ while other $\mathrm{Zr}(\mathrm{IV})$ species exist in the tetragonal phase of zirconia(see XRD).

The textural properties of the sulfated silica-zirconia samples are given in Table 1 . The pore diameter $\left(D_{\mathrm{p}}\right)$ and specific pore volume $\left(V_{\mathrm{p}}\right)$ of $\mathrm{SiO}_{2}-\mathrm{SZ}(2, x \mathrm{~S})$ increase as the $\mathrm{SO}_{4}{ }^{2-} / \mathrm{Zr}$ molar ratio is decreased to 0.25 . On the other hand, the pore wall thickness $\left(T_{\mathrm{w}}\right)$ gradually deceases with lowering of the $\mathrm{SO}_{4}{ }^{2-}$ / $\mathrm{Zr}$ molar ratio. All of the calcined products give pore diameters around $10 \mathrm{~nm}$ and specific surface area at 500 $600 \mathrm{~m}^{2} / \mathrm{g}$. Table 


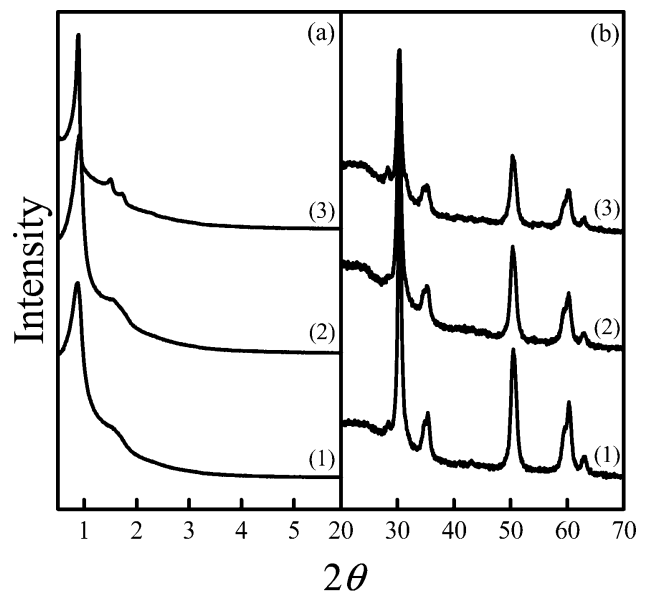

Figure 4. XRD patterns of $\mathrm{SiO}_{2}-\mathrm{SZ}(y, 1 \mathrm{~S})$ at $y=\mathrm{Si} / \mathrm{Zr}$ molar ratios of (1) 2, (2) 3, and (3) 4. (a) The small angle and (b) the high angle.

1 also shows the zirconium content in the calcined samples: $\mathrm{Si} / \mathrm{Zr}=3.01$ for $\mathrm{SO}_{4}{ }^{2-} / \mathrm{Zr}=1$ slightly higher than the $\mathrm{Zr}$ yield of $\mathrm{Si} / \mathrm{Zr}=3.6$ for $\mathrm{SO}_{4}{ }^{2-} / \mathrm{Zr}=0.5$ and further increases to 6.56 for $\mathrm{SO}_{4}{ }^{2-} / \mathrm{Zr}=0.25$. The change in the $\mathrm{Si} / \mathrm{Zr}$ molar ratio was investigated at a fixed molar ratio of $\mathrm{SO}_{4}{ }^{2-} / \mathrm{Zr}=1$. From Table 1 , the $\mathrm{Si} / \mathrm{Zr}$ molar ratios of the calcined $\mathrm{SiO}_{2}-\mathrm{SZ}(y, 1 \mathrm{~S})$ products are higher than the $\mathrm{Si} / \mathrm{Zr}$ molar ratios in the synthesis gels. It is suggested that not all $\mathrm{Zr}$ (IV) can form zirconium sulfated polyoxo species under such an acidic condition. As seen in Table 1, increasing $\mathrm{Zr}$ content in the synthesis gel also enhances the $\mathrm{Zr}$ content in the product. The $\mathrm{Si} / \mathrm{Zr}$ molar ratio in the calcined sample is 6.74 for $\mathrm{SiO}_{2}-\mathrm{SZ}(4,1 \mathrm{~S})$, but for $\mathrm{SiO}_{2}$ $\mathrm{SZ}(2,1 \mathrm{~S})$, the $\mathrm{Si} / \mathrm{Zr}$ molar ratio in the calcined sample decreases to 3.01. All of these results suggest that higher molar ratio of $\mathrm{SO}_{4}{ }^{2-} / \mathrm{Zr}$ favors more zirconium incorporation onto mesoporous SBA-15 without affecting much the textural properties.

Effect of Changing Si/Zr Ratio. The mesoporous structure of $\mathrm{SiO}_{2}-\mathrm{SZ}(y, 1 \mathrm{~S})$ is characterized in the small angle XRD patterns of Figure 4a. The small angle XRD pattern of calcined $\mathrm{SiO}_{2}-$ SZ(4, 1S) exhibits three well-resolved peaks which are indexed to the (100), (110), and (200) reflections of the 2-D hexagonal P6mm structure. As $\mathrm{Si} / \mathrm{Zr}$ molar ratios are decreased from 4 to 2 , the intensity of (100) peaks decreases and the peaks of (110) and (200) are broadened with increasing $\mathrm{Zr}$ incorporation. The crystal characteristic of zirconia is exhibited in the high angle XRD patterns of Figure $4 \mathrm{~b}$. At a fixed $\mathrm{SO}_{4}{ }^{2-} / \mathrm{Zr}$ molar ratio, all of the $\mathrm{SiO}_{2}-\mathrm{SZ}(y, 1 \mathrm{~S})$ samples show peaks characteristic of tetragonal zirconia and the peak widths are gradually increasing with increasing $\mathrm{Si} / \mathrm{Zr}$ molar ratios.

$\mathrm{N}_{2}$ adsorption-desorption isotherms of $\mathrm{SiO}_{2}-\mathrm{SZ}(y, 1 \mathrm{~S})$ are shown in Figure 5 and the texture properties are listed in Table 1. All three samples have noticeable hysteresis loops in the type IV isotherms. The surface areas and pore volumes of $\mathrm{SiO}_{2}-$ $\mathrm{SZ}(y, 1 \mathrm{~S})$ slightly decrease as the $\mathrm{Si} / \mathrm{Zr}$ ratio in the synthesis gel is increased. From the small angle XRD patterns and $\mathrm{N}_{2}$ adsorption-desorption isotherms, $\mathrm{SiO}_{2}-\mathrm{SZ}(2,1 \mathrm{~S})$ still keeps a well-order mesostructure. It indicates that $\mathrm{SiO}_{2}-\mathrm{SZ}$ can be prepared with high $\mathrm{Zr}$ loadings while keeping well-ordered mesostructures.

From the UV-visible diffuse reflectance spectra shown in Figure 6, the $\mathrm{SiO}_{2}-\mathrm{SZ}(y, 1 \mathrm{~S})$ samples prepared at different $\mathrm{Si}$ / $\mathrm{Zr}$ molar ratio are found to have absorptions at 212 and 230 $\mathrm{nm}$, indicating isolated $\mathrm{Zr}(\mathrm{IV})$ species in the mesoporous silica wall and nanocrystals of zirconia on mesoporous silica.

Transmission electron micrograph (TEM) of $\mathrm{SiO}_{2}-\mathrm{SZ}(2,1 \mathrm{~S})$ calcined at $650{ }^{\circ} \mathrm{C}$ is shown in Figure 7 . Well-ordered channels

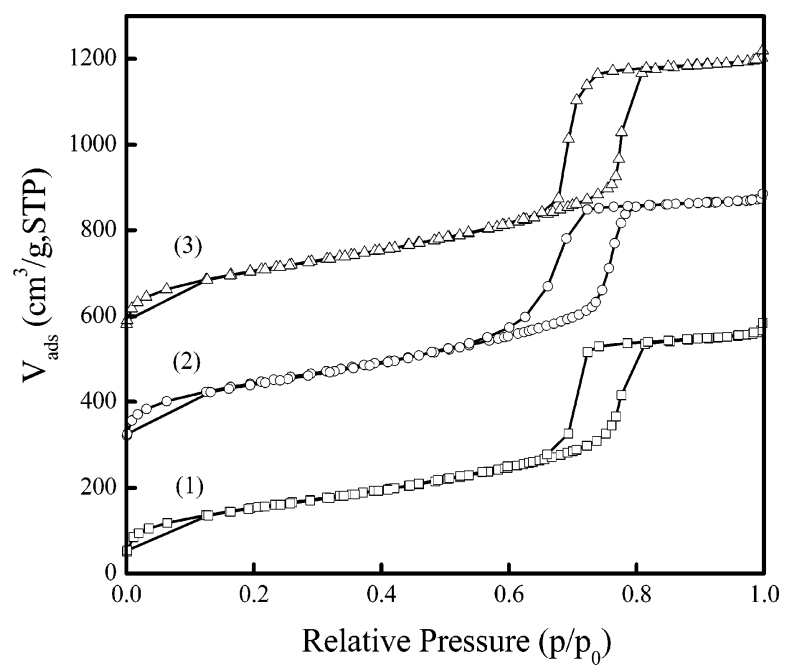

Figure 5. Nitrogen adsorption isomerms of $\mathrm{SiO}_{2}-\mathrm{SZ}(y, 1 \mathrm{~S})$ at $y=$ $\mathrm{Si} / \mathrm{Zr}$ molar ratios of (1) 2, (2) 3, and (3) 4.

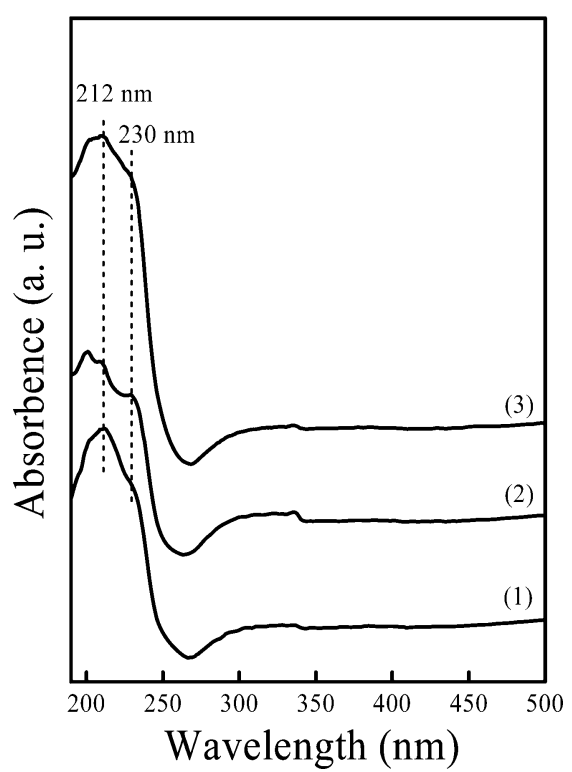

Figure 6. UV - vis DR spectra of $\mathrm{SiO}_{2}-\mathrm{SZ}(y, 1 \mathrm{~S})$ at $y=\mathrm{Si} / \mathrm{Zr}$ molar ratios of (1) 2, (2) 3, and (3) 4.

with continuous walls are seen clearly, and zirconia species are obviously scattered into the mesopores. Some zirconia nanoparticles exists outside the channel of mesoporous silica, however.

3.2. Acidity. Acidity of the catalyst was investigated by measuring the temperature-programmed desorption of $\mathrm{NH}_{3}$. $\mathrm{NH}_{3}-$ TPD profiles of $\mathrm{SiO}_{2}-\mathrm{SZ}(2,1 \mathrm{~S})$ and unsupported SZ catalysts are shown in Figure 8. Both show broad distributions of acid site strengths. In order to compare the acidity quantitatively, we adjusted same amount of $50 \mathrm{mg}$ of SZ was contained in both catalysts in the experiments. In the case of unsupported SZ, the desorption peak is mainly distributed on the region of $210 \sim 290{ }^{\circ} \mathrm{C}$ corresponding to weak acid sites. As zirconia is incorporated onto the mesoporous silica, the intensity of desorption peak was greatly enhanced which means a larger amount acid sites. There is a desorprtion peak at $\sim 458{ }^{\circ} \mathrm{C}$ for $\mathrm{SiO}_{2}-\mathrm{SZ}(2,1 \mathrm{~S})$, indicating the formation of the strong acid sites. Previously, Lopez et al. ${ }^{24}$ measured the acidity of tungstated zirconia by both $\mathrm{NH}_{3}-$ TPD and ion exchange/ titration method and concluded that the titration result corroborates better with rates of esterification. Thus, the acidities of the catalysts were also measured by titration with $\mathrm{NaOH}$ as 


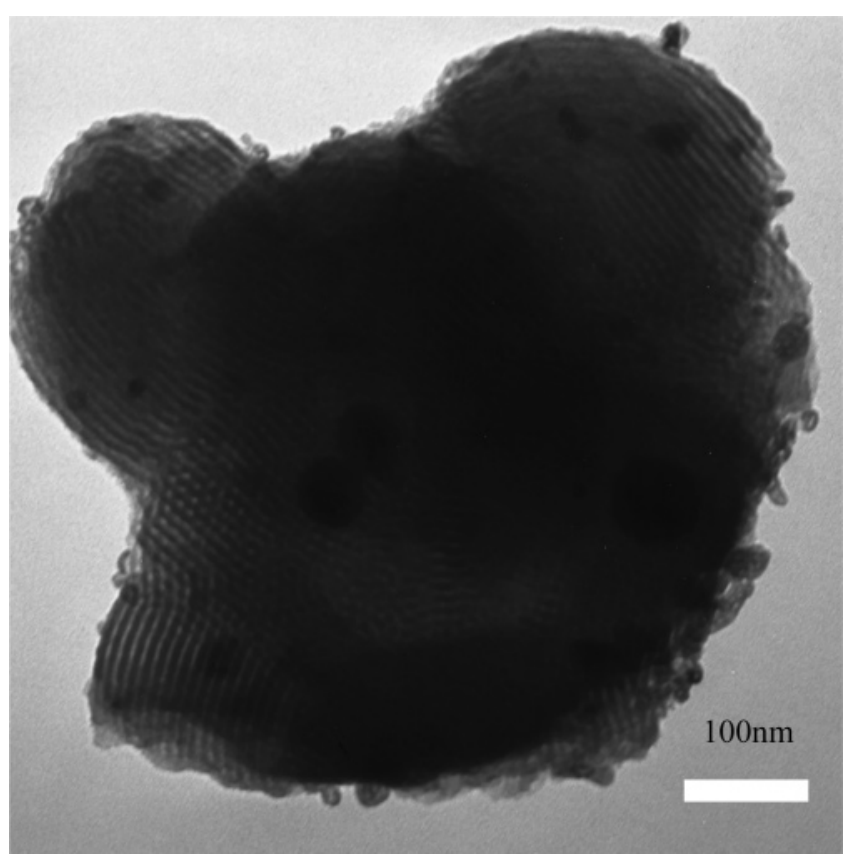

Figure 7. TEM micrograph of the SZ/SBA-15(2, 1S) sample.

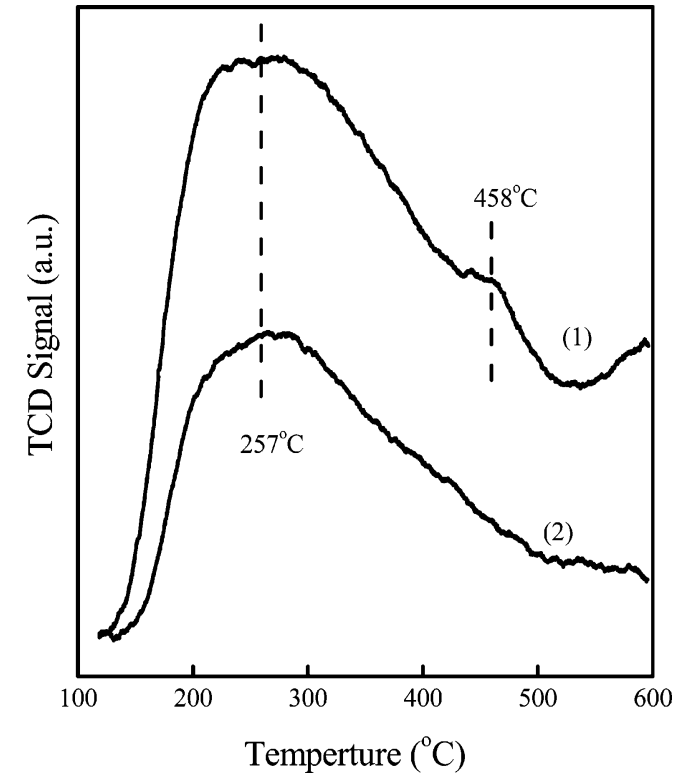

Figure 8. $\mathrm{NH}_{3}$ temperature-programmed-desorption profiles of (1) $\mathrm{SiO}_{2}-\mathrm{SZ}(2,1 \mathrm{~S})$ and (2) SZ.

TABLE 2: Acidity by Titration of $\mathrm{SiO}_{2}-\mathrm{SZ}(2,1 \mathrm{~S})$ and $\mathrm{SZ}$

\begin{tabular}{ccc}
\hline \multicolumn{1}{c}{ catalyst } & $\begin{array}{c}\mathrm{S} / \mathrm{Zr} \\
\text { molar ratio }\end{array}$ & $\begin{array}{c}\text { acidity by titration } \\
\left(\mu \mathrm{mol} / \mathrm{g} \mathrm{ZrO}_{2}\right)\end{array}$ \\
\hline $\mathrm{SiO}_{2}-\mathrm{SZ}(2,1 \mathrm{~S})$ & 0.044 & 1260 \\
$\mathrm{SZ}$ & 0.15 & 720
\end{tabular}

listed in Table 2. An extraordinarily high value of $1260 \mu \mathrm{mol} / \mathrm{g}$ $\mathrm{ZrO}_{2}$ acid sites are detected in $\mathrm{SiO}_{2}-\mathrm{SZ}(2,1 \mathrm{~S})$, much higher than the amount of $720 \mu \mathrm{mol} / \mathrm{g} \mathrm{ZrO}_{2}$ acid sites found in unsupported SZ. This high density of acid sites is comparable with the recently reported very high density of acid sites reported for carbonized glucose. ${ }^{\text {b }}$

3.3. Catalytic Activities. The esterification of long-chain free fatty acids was carried out at $68^{\circ} \mathrm{C}$ for $6 \mathrm{~h}$ over the directsynthesis sulfated silica-zirconia, silica-zirconia, and unsupported SZ materials. The conversion results at a reaction time of $6 \mathrm{~h}$ are shown in Table 3. For the purpose of comparison, $\mathrm{SiO}_{2}-\mathrm{SZ}(2,1 \mathrm{~S})$ and unsupported $\mathrm{SZ}$ were adjusted to contain

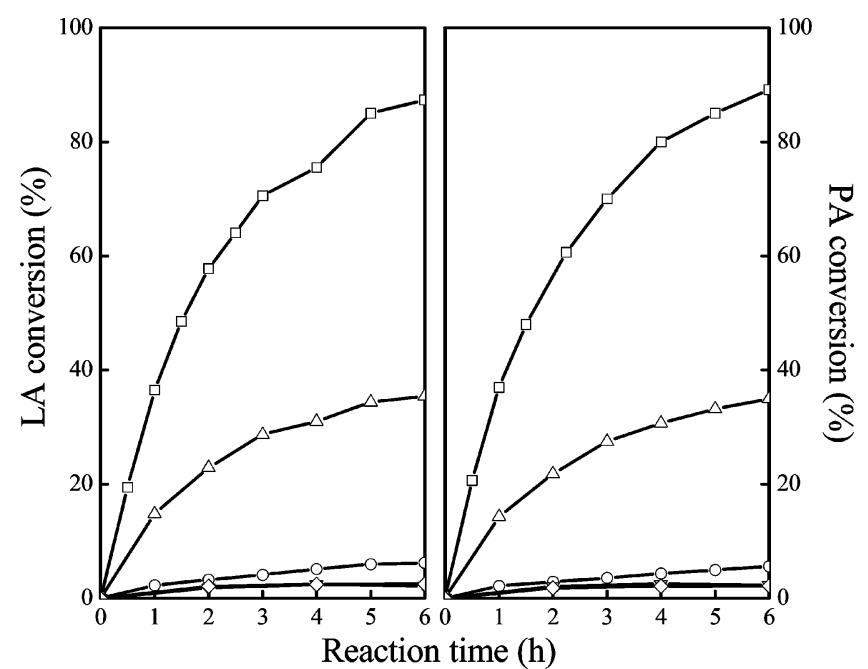

Figure 9. Catalytic performance of esterification over various catalysts. $-\square-\mathrm{SiO}_{2}-\mathrm{SZ}(2,1 \mathrm{~S}) ;-\mathrm{O}-\mathrm{SiO}_{2}-\mathrm{ZrO}_{2}(2,0 \mathrm{~S}) ;-\Delta-\mathrm{SZ} ;-\nabla-$ SBA-15; $-\diamond-$ no catalyst.

TABLE 3: Esterification of Fatty Acid with Methanol over $\mathrm{SiO}_{2}-\mathrm{SZ}^{a}$

\begin{tabular}{lcc}
\hline \multicolumn{1}{c}{ catalyst } & $\begin{array}{c}\text { LA conversion } \\
(\%)\end{array}$ & $\begin{array}{c}\text { PA conversion } \\
(\%)\end{array}$ \\
\hline $\mathrm{SiO}_{2}-\mathrm{SZ}(2,1 \mathrm{~S})$ & 87.4 & 89.2 \\
$\mathrm{SiO}_{2}-\mathrm{SZ}(2,0.5 \mathrm{~S})$ & 38.1 & 39.4 \\
$\mathrm{SiO}_{2}-\mathrm{SZ}(2,0.25 \mathrm{~S})$ & 33.1 & 33.6 \\
$\mathrm{SiO}_{2}-\mathrm{ZrO}_{2}(2,0 \mathrm{~S})$ & 6.20 & 5.62 \\
$\mathrm{SiO}_{2}-\mathrm{SZ}(3,1 \mathrm{~S})$ & 52.1 & 53.3 \\
$\mathrm{SiO}_{2}-\mathrm{SZ}(4,1 \mathrm{~S})$ & 27.0 & 27.9 \\
${ }^{a}$ Data obtained after reaction $6 \mathrm{~h}$ &
\end{tabular}

the same amount of sulfated zirconia. The calculated conversion of free fatty acid is based on the $100 \%$ selectivity to the fatty acid methyl ester. $\mathrm{SiO}_{2}-\mathrm{SZ}(2,1 \mathrm{~S})$ shows an extraordinarily high catalytic performance with the LA conversion of $87.4 \%$ and PA conversion of $89.2 \%$. As one would have expected, increasing the $\mathrm{Si} / \mathrm{Zr}$ (decreasing $\mathrm{Zr}$ loading) decreases the catalytic activity. Lesser sulfation also gives less conversion of fatty acid. $\mathrm{SiO}_{2}-\mathrm{SZ}(2, x \mathrm{~S})(x>0)$ materials present higher catalytic activity for esterification than $\mathrm{SiO}_{2}-\mathrm{ZrO}_{2}(2,0 \mathrm{~S})$. Unsulfated $\mathrm{SiO}_{2}-\mathrm{ZrO}_{2}(2,0 \mathrm{~S})$ mixed oxides show some weak catalytic activity with the LA conversion of $6.2 \%$ and PA conversion of $5.6 \%$. For comparison, the cases of unsupported SZ, pure silica SBA-15 and no catalysts were also examined for the esterification. With no catalyst or with pure silica SBA15 , no activity for the conversion of LA and PA were found. At a reaction time of $6 \mathrm{~h}$, the conversions of LA and PA over unsupported SZ are $35.4 \%$ and $35.0 \%$, respectively. Figure 9 shows the time evolution of the conversion of the fatty acids as catalyzed by the solid acids. The reactivities for the two fatty acids, lauric acid and palmitic acid, are very similar showing no chain length effect. Recently, in a study of esterification catalyzed by glucose $/ \mathrm{H}_{2} \mathrm{SO}_{4}$ derived carbon catalyst, ${ }^{25}$ the formation of methyl palmtate, oleate, and stearate gave almost identical rates. There is also no chain length-dependence of activity.

The initial conversions in Figure 9 are quite linear, and we can calculate the initial reaction rates to compare with literature values for other catalysts. The initial rate of methyl laurate (LAME) formation (at $68^{\circ} \mathrm{C}$ ) is about $175 \mu \mathrm{mol} / \mathrm{min} / \mathrm{g}$ cat over $\mathrm{SiO}_{2}-\mathrm{SZ}(2,1 \mathrm{~S})$. In comparison, the initial rate of LAME formation is about $125 \mu \mathrm{mol} / \mathrm{min} / \mathrm{g}$ cat over SZ. Methyl palmtate(PAME) gave similar rates. As we have presented in 


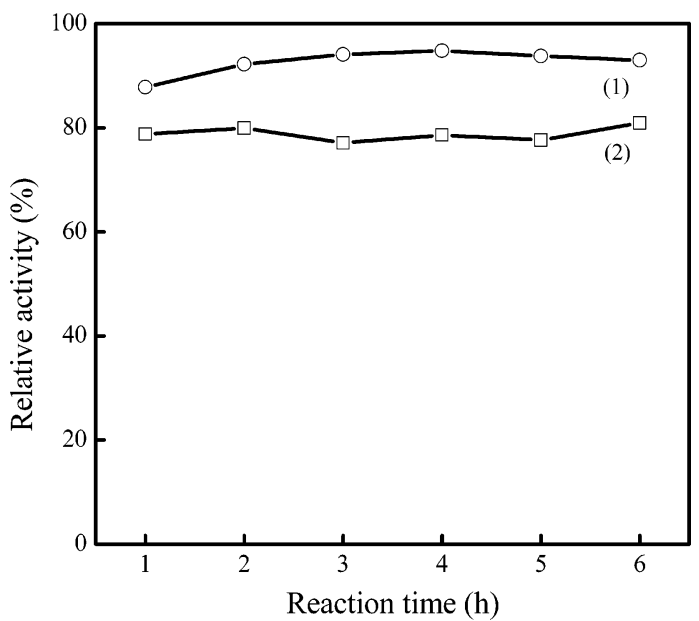

Figure 10. Effect of water on esterification over (1) $\mathrm{SiO}_{2}-\mathrm{SZ}(2,1 \mathrm{~S})$ and (2) SZ.

Table 3, the difference in the final conversion at $6 \mathrm{~h}$ is even bigger. In a recent study of esterification of methyl oleate formation at $80{ }^{\circ} \mathrm{C}$, Zong et al. found a reaction rate of 143 $\mu \mathrm{mol} / \mathrm{min} / \mathrm{g}$ cat for sulfated zirconia and $478 \mu \mathrm{mol} / \mathrm{min} / \mathrm{g}$ cat for glucose $/ \mathrm{H}_{2} \mathrm{SO}_{4}$-derived carbon catalyst. ${ }^{25}$ Since we are measuring rates at a lower temperature of $68{ }^{\circ} \mathrm{C}$, our $\mathrm{SiO}_{2}-\mathrm{SZ}$ catalyst is definitely much more active than sulfated zirconia, niobic acid, amberlyst-15 catalysts reported in ref 25 , and probably not far from the excellent glucose-derived catalyst.

To investigate the water effect on the catalytic performance of $\mathrm{SiO}_{2}-\mathrm{SZ}(2,1 \mathrm{~S})$ and $\mathrm{SZ}$, a small amount of water was added to the mixture of catalysts and reactants at the level of 3600 ppm (weight percent). Under the same reaction conditions, the esterification containing water is compared with the case without adding water. Figure 10 shows the effect of water on the esterification of lauric acid with methanol over $\mathrm{SiO}_{2}-\mathrm{SZ}(2,1 \mathrm{~S})$ and SZ. The relative activity means the ratio of the conversion of esterification containing $3600 \mathrm{ppm}$ water to the conversion of esterification free of water at the same reaction time. Decreased activities are observed in the water-added esterification for both $\mathrm{SiO}_{2}-\mathrm{SZ}(2,1 \mathrm{~S})$ and $\mathrm{SZ}$. The relative activity of $\mathrm{SiO}_{2}-\mathrm{SZ}(2,1 \mathrm{~S})$ is obviously higher than that of $\mathrm{SZ}$, which suggests that $\mathrm{SiO}_{2}-\mathrm{SZ}(2,1 \mathrm{~S})$ exhibits better tolerance to water.

\section{Discussions}

The solid acid catalyst system, sulfated zirconia, is rather complex in its acidic site distribution depending on methods of preparation, pretreatments, and type of reactions. Notwithstanding its long history of investigation, we do not yet have a complete understanding of the strong acidity of sulfated zirconia. However, we would like to discuss some possible origins of its excellent catalytic behavior for the esterification reaction. There are several observations we would like to make in this section.

First, we comment on the method of preparation of the catalysts. Previously, in making acid catalysts for alkane isomerization, we used postsynthesis methods of impregnation of sulfated zirconia onto the surface of mesoporous silica. ${ }^{11}$ In that method, the resulting zirconia was found to be either nanoparticles or monolayer on the surface of silica. In this paper, we used a direct method of coprecipitation, We found nanoparticles of tetragonal zirconia, but we also have framework incorporation of zirconia. The resulting silica-zirconia materials are weakly acidic, and sulfation creates more surface acidity. Also we note that the mesoporous SBA-15 gives bigger pores $(8 \sim 10 \mathrm{~nm})$ and a larger pore volume in contrast to our previous zirconia supported on MCM-41.11c The big pores are necessary for the liquid-state transport of long chain fatty acid.

Second, we would like to discuss the acidity of the solid acid catalysts employed in this work. The esterification reaction of the fatty acid has been shown to be a Brønsted acid-catalyzed reaction. ${ }^{24}$ We have measured a higher density of acid site density in the $\mathrm{SiO}_{2}-\mathrm{SZ}(2,1 \mathrm{~S})$ catalyst than the unsupported sulfated zirconia. It seems there are two sources of the acid sites in the sulfated silica-zirconia materials, one from the nanocrystaline sulfated zirconia itself and the other comes from the mixed silica-zirconia oxides. Rosenberg and co-workers found Brønsted acid sites could be detected on the sulfate-free silica-zirconia mixed oxides by infrared spectroscopic and thermogravimetric techniques. ${ }^{26,27}$ These unsulfated materials showed some low activity in the protonation of the $\mathrm{C}=\mathrm{C}$ group. It would appear that the addition of sulfate leads to the formation of new and stronger Bronsted acid sites on $\mathrm{SiO}_{2}-\mathrm{SZ}(2, x \mathrm{~S})(x$ $>0)$ materials. On the other hand, in $\mathrm{SiO}_{2}-\mathrm{ZrO}_{2}(2,0 \mathrm{~S})$, the crystal phases of zirconia are not observed and the $\mathrm{Zr}$ (IV) species are incorporated into the framework of the mesostructured silica, as confirmed by XDR and UV- visible diffuse reflectance spectroscopy. The acid sites are contributed by zirconium (IV) species incorporated in silica. The acidity of $\mathrm{SiO}_{2}-\mathrm{ZrO}_{2}(2,0 \mathrm{~S})$ is however weak, so that a small but nonnegligible activity could be observed. Isomorphic $\mathrm{Zr}$-substituted mesoporous silicas have been reported previously. ${ }^{23,28,29}$ This material shows a relatively low catalytic activity in acidcatalyzed reactions. Upon sulfation, Xiao and co-workers ${ }^{30}$ showed that sulfated silica-zirconia exhibits high activities in catalytic cracking of cumene and tri-isopropyl benzene. This material is similar to our sulfated $\mathrm{SiO}_{2}-\mathrm{ZrO}_{2}$, and their catalytic result seems to agree with our conclusion of higher acidic catalytic activity. Upon high loadings of sulfur and zirconia in the synthesis gel, the tetragonal phase of zirconia would form. It is known that the tetragonal zironia is the catalytically more active form of zirconia. ${ }^{31}$ The tetragonal $\mathrm{ZrO}_{2}$ was formed as sulfate groups are added to the synthesis gel. It is possible that the addition of sulfate may enhance the phase segregation by extracting zirconia to the surface of the mixed oxides and stabilize the tetragonal phase.

Compared to unsupported sulfated zirconia, $\mathrm{SiO}_{2}-\mathrm{SZ}(2,1 \mathrm{~S})$ exhibits much improved catalytic activity for esterification. As seen in Table 2, the molar ratio of $\mathrm{S} / \mathrm{Zr}$ in $\mathrm{SiO}_{2}-\mathrm{SZ}(2,1 \mathrm{~S})$ is 0.044 , much lower than the molar ratio of 0.15 of $\mathrm{S} / \mathrm{Zr}$ presented in unsupported $\mathrm{SZ}$. However, $\mathrm{SiO}_{2}-\mathrm{SZ}(2,1 \mathrm{~S})$ generates more acid sites (Figure 8 and Table 2) at this lower sulfate density. It is suggested that the high catalytic activity of $\mathrm{SiO}_{2}-\mathrm{SZ}(2$, 1S) did not display the corresponding high sulfate density. Pure silica shows little acidity. However, mesoporous silica as a support can provide high surface area, porosity, and thermal stability. ${ }^{13,14} \mathrm{SiO}_{2}-\mathrm{SZ}(2,1 \mathrm{~S})$ prepared by the direct-synthesis method can facilitate better dispersion of zirconia into the mesoporous silica resulting in a higher number of accessible active sites on the inner surface of the pore wall.

Third, another reason of better performance of SBA-15 supported $\mathrm{SiO}_{2}-\mathrm{SZ}$ catalyst is its better tolerance of water. It is known that the pure SBA-15 materials lack acid sites and that the acid sites of $\mathrm{SiO}_{2}-\mathrm{SZ}(2,1 \mathrm{~S})$ are mainly contributed by sulfated zirconia. Water can inhibit the reaction because it is the product in the esterification of free fatty acid with methanol, shifting the equilibrium toward the reactants. ${ }^{32}$ Also water produced may block the acid surface sites. As water is produced in the esterification, the acid sites interacting with water result in a loss of part of the acid sites and lowered its 
catalytic activity. The lost acid sites of SZ are not recovered in the esterifiction; the conversion was kept at $\sim 78 \%$ during the rest of reaction times of $6 \mathrm{~h}$. However, the surface of SBA-15 is quite hydrophilic. For $\mathrm{SiO}_{2}-\mathrm{SZ}(2,1 \mathrm{~S})$, near the catalytic sites, the neighboring silica surface of SBA-15 can help remove the water produced. Water produced in esterification can be quickly absorbed by the large silica surface. Some acid sited could thus be recovered. The water-addition experiment seems to confirm this conjecture. At the initial stage, parts of the acid sites are covered by water so the relative activity is $\sim 85 \%$ at $1 \mathrm{~h}$ of reaction time. For a longer reaction time, some water would be excluded from the acid sites by the hydrophilic silica, and the relative activity increases further to $\sim 93 \%$ (Figure 10). It is this water-tolerant property of the catalyst that gives a stable catalytic behavior in the esterification reaction.

In conclusion, we have developed a series of mesoporous sulfated silica-zirconia materials as a solid acid catalyst. The materials are shown to possess a higher density of acidic sites in comparison to the unsupported sulfated zirconia. This results in excellent catalytic activity and stability for the esterification of long chain fatty acids.

Acknowledgment. This work was supported by a grant from the National Science Council of Taiwan through the program of Academic Excellent (NSC-94-2752-M-002-004-PAE).

\section{References and Notes}

(1) Lotero, E.; Liu, Y.; Lopez, D. E.; Suwannakarn, K.; Bruce, D. A.; Goodwin, J. G. Ind. Eng. Chem. Res. 2005, 44, 5353.

(2) Hoydonckx, H. E.; De Vos, D. E.; Chavan, S. A.; Jacobs, P. A. Top. Catal. 2004, 27, 83.

(3) Kulkarni, M. G.; Gopinath, R.; Meher, L. C.; Dalai, A. K. Green Chem. 2006, 8, 1056.

(4) Di Serio, M.; Tesser, R.; Dimiccoli, M.; Cammarota, F.; Nastasi, M.; Santacesaria, E. J. Mol. Catal. A 2005, 239, 111.

(5) Zullaikah, S.; Lai, C. C.; Ramjan, S.; Ju, Y. S. Bioresour. Technol. 2005, 96, 1889.

(6) Bondioli, P. Top. Catal. 2004, 27, 77.

(7) (a) Toda, M.; Takagaki, A.; Okamura, M.; Kondo, J. N.; Hayashi, S.; Domen, K.; Hara, M. Nature 2005, 438, 178. (b) Takagaki, A.; Toda, M.; Okamura, M.; Kondo, J. N.; Hayashi, S.; Domen, K.; Hara, M. Catal. Today 2006, 116, 157.

(8) Kiss, A. A.; Dimian, A. C.; Rothenberg, G. Adv. Synth. Catal. 2006, 348,75 .
(9) (a) Mbaraka, I. K.; Shanks, B. H. J. Catal. 2005, 229, 365. (b) Feng, Y. F.; Yang, X. Y.; Yang, D.; Du, Y. C.; Zhang, Y. L.; Xiao, F. S. J. Phys. Chem. B 2006, 110, 14142.

(10) Kiss, A. A.; Omata, F.; Dimian, A. C.; Rothenberg, G. Top. Catal. 2006, 40, 141.

(11) (a) Wang, W.; Chen, C. L.; Xu, N. P.; Mou, C. Y. Green Chem. 2002, 4, 257. (b) Chen, C. L.; Cheng, S. F.; Lin, H. P.; Wong, S. T.; Mou, C. Y. Appl. Catal. A 2001, 215, 21. (c) Chen, C. L.; Li, T.; Cheng, S. F.; Lin, H. P.; Bhongale, C. J.; Mou, C. Y. Microporous Mesoporous Mater. 2001, 201.

(12) Mbaraka, I. K.; Radu, D. R.; Lin, V. S.; Shanks, B. H. J. Catal. 2003, 219, 365

(13) Liu, Y.; Lotero, E.; Goodwin, J. G. J. Catal. 2006, 243, 221.

(14) (a) Zhao, D.; Feng, J.; Huo, Q.; Nelosh, N.; Fredrikson, G.; Chmelka, B. F.; Stucky, G. D. Science 1998, 120, 278. (b) Zhao, D.; Huo, Q.; Feng, J.; Chmelka, B. F.; Stucky, G. D. J. Am. Chem. Soc. 1998, 120, 6024.

(15) Li, T.; Wong, S. T.; Chao, M. C.; Lin, H. P.; Mou, C. Y.; Cheng, S. Appl. Catal. A 2004, 261, 211.

(16) Wang, J. H.; Mou, C. Y. Appl. Catal. A 2005, 286, 128.

(17) Landau, M. V.; Titelman, L.; Vradman, L.; Wilson, P. Chem. Commun. 2004, 24, 594.

(18) Selvaraj, M.; Lee, T. G. J. Phys. Chem. B 2006, 110, 21793.

(19) Vinu, A.; Sirnivasu, P.; Miyahara, M.; Ariga, K. J. Phys. Chem. B 2006, 110,801 .

(20) El Brahimi, M.; Durand, J.; Cot, L. Eur. J. Solid State Inorg. Chem. 1988, 25, 185.

(21) Ciesla, U.; Fröba, M.; Stucky, G.; Schüth, F. Chem. Mater. 1999, $11,227$.

(22) Tuel, A.; Gontie, S.; Teissier, R. Chem. Commun. 1996, 5, 651.

(23) Morey, M. S.; Stucky, G. D.; Schwarz, S.; Fröba, M. J. Phys. Chem. B 1999, 103, 2037.

(24) Lopez, D. E.; Suwannakarn, K.; Bruce, D. A.; Goodwin, J. G. J. Catal. 2007, 247, 43.

(25) Zong, M. H.; Duan, Z. Q.; Lou, W. Y.; Smith, T. J.; Wu, H. Green Chem. 2007, 9, 434.

(26) Rosenberg, D. J.; Anderson, J. A. Catal. Lett. 2002, 83, 59.

(27) Rosenberg, D. J.; Bachiller-Baeza, B.; Dines, T. J.; Anderson, J. A. J. Phys. Chem. B 2003, 107, 6526.

(28) Chen, S. Y.; Jang, L. Y.; Cheng, S. F. Chem. Mater. 2004, 16, 4174.

(29) Chao, M. C.; Lin, H. P.; Mou, C. Y.; Cheng, B. W.; Cheng, C. F. Catal. Today 2004, 97, 81.

(30) Du, Y. C.; Sun, Y. Y.; Di, Y.; Zhao, L.; Liu, S.; Xiao, F. S. J. Porous Mater. 2006, 13, 163.

(31) Morterra, C.; Cerrato, G.; Ardizzone, B.; Bianchi, C. L.; Signoretto, M.; Pinna, F. Phys. Chem. Chem. Phys. 2002, 4, 3136.

(32) (a) Liu, Y.; Lotero, E.; Goodwin, J. G. J. Catal. 2006, 242, 187. (b) Liu, Y.; Lotero, E.; Goodwin, J. G. J. Mol. Catal. A 2005, 245, 132. 